\title{
Prevalence and Its Feto-Maternal Outcome in Placental Abruption: A Retrospective Study for 5 Years from Dubai Hospital
}

\author{
Shabnam Saquib Lama Khalid Hamza Azza AlSayed Faiza Saeed \\ Masuma Abbas \\ Department of Obstetrics and Gynecology, Dubai Hospital, Dubai Health Authority, Dubai, UAE
}

\section{Keywords}

Disseminated intravascular coagulation - Maternal morbidity · Perinatal morbidity · Pre-eclampsia $\cdot$ Placental abruption

\begin{abstract}
Introduction: Placental abruption (PA) is a major obstetric complication leading to increased risk of maternal and neonatal morbidity and mortality globally. This study aims to determine the prevalence and its feto-maternal outcome in cases of placental abruption in our population. Methods: A retrospective descriptive case study was conducted from January 2013 till December 2017 in Dubai Hospital, Dubai, UAE. All patients admitted with suspicion of placental abruption at 28 weeks of gestation and beyond were included in the study. The clinical information like maternal age, parity, antenatal risk factors, gestational age at delivery, mode of delivery, postpartum complications and perinatal outcome were studied. Result: A total of 15,079 deliveries occurred during the study period; PA accounted for $0.61 \% .62 \%$ of the women had revealed abruption and $38 \%$ had concealed abruption. The antenatal risk factors associated with abruption were diabetes (26\%), chronic hypertension (2.2\%), pre-ec-
\end{abstract}

\begin{tabular}{ll}
\hline KARGER & (c) 2020 The Author(s) \\
& Published by S. Karger AG, Basel \\
karger@karger.com & This article is licensed under the Creative Commons Attribution- \\
www.karger.com/dmj & NonCommercial-NoDerivatives 4.0 International License (CC BY- \\
& NC-ND) (http://www.karger.com/Services/OpenAccessLicense). \\
Usage and distribution for commercial purposes as well as any dis- \\
tribution of modified material requires written permission.
\end{tabular}

lampsia (19.5\%), previous cesarean section (26\%), and multiple pregnancy (9.8\%). Cesarean section was the mode of delivery in $78 \%$ of abruption cases. $33 \%$ had postpartum hemorrhage and $20 \%$ had received blood products. Adverse fetal outcomes were as follows: $51 \%$ of the cases had preterm delivery, $47 \%$ of the babies had a birth weight of less than $2.5 \mathrm{~kg}, 8$ cases died of intrauterine fetal death and there was 1 neonatal death. Conclusion: Even when being aware of the risk factors, placental abruption still remains unpredictable or unpreventable. Having better equipped obstetric and neonatal units with multidisciplinary management can improve both maternal and perinatal outcome in cases of placental abruption.

(c) 2020 The Author(s)

Published by S. Karger AG, Basel

\section{Introduction}

Placental abruption (PA) is defined as the complete or partial separation of a normally implanted placenta before delivery. It is a serious multifactorial obstetric complication, and its etiopathogenetic mechanism is not yet entirely understood [1]. PA occurs in about $0.38-1 \%$ of singleton births, and in $1-2 \%$ of twin pregnancies $[2,3]$. 


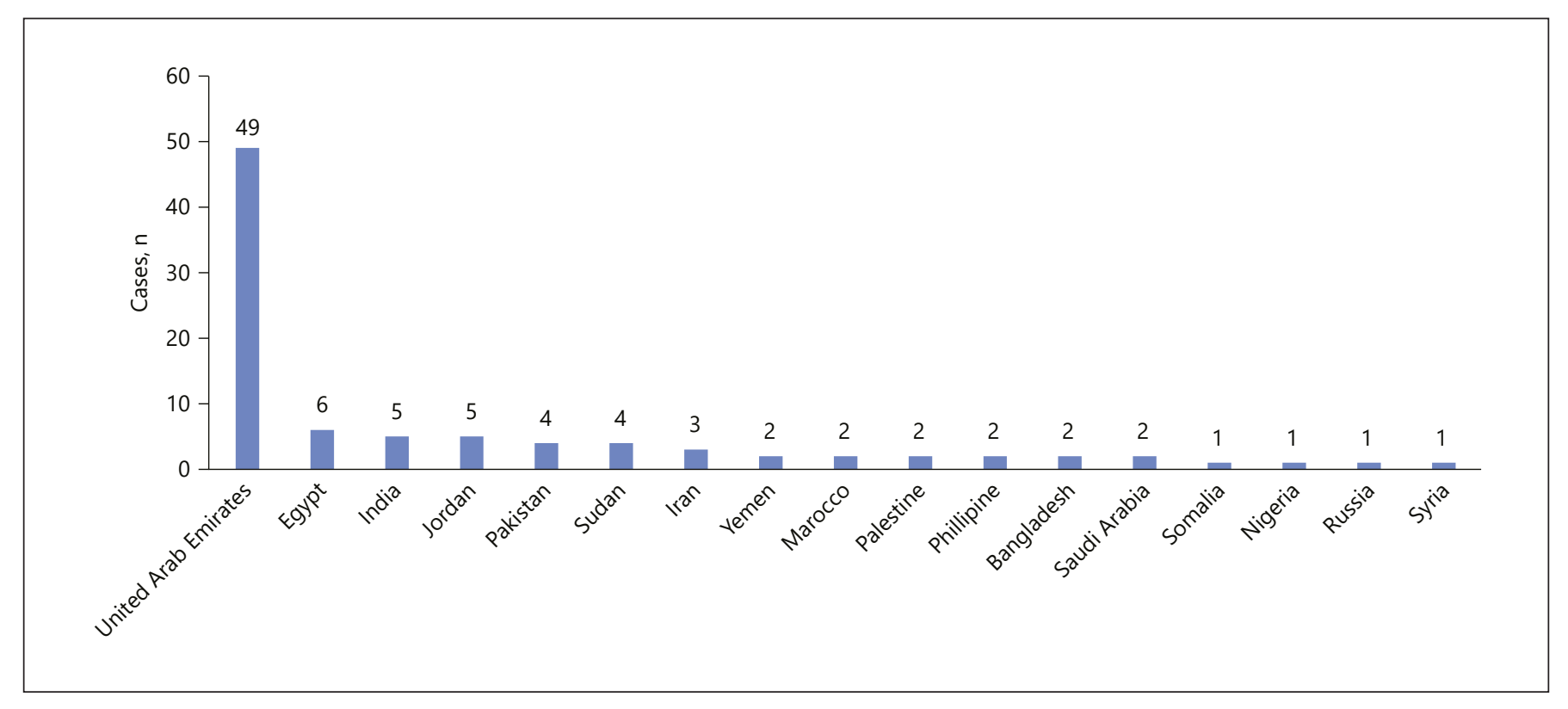

Fig. 1. Placental abruption cases in different nationalities.

It is a major obstetric complication associated with an increased risk of fetal and maternal morbidity and mortality globally, especially in developing countries where the incidence varies from 4 to $6 \%[4,5]$.

PA accounts for $20-25 \%$ of antepartum hemorrhage, resulting in increased maternal peripartum risk factors like disseminated intravascular coagulopathy, postpartum hemorrhage, severe maternal shock, emergency hysterectomy, acute renal failure and maternal death [3, 6-8]. Adverse fetal outcomes like intrauterine growth restriction, preterm birth, low birth weight, fetal distress, low Apgar score, transfer to neonatal intensive care unit, stillbirth, congenital anomalies and perinatal death ranging from 4.4 to $67.3 \%$ are also observed in cases of PA $[9,10]$.

Although PA occurrence is often unpredictable, several risk factors have been associated such as previous history of PA, extremes of maternal age, previous history of cesarean section, grand multiparity, multiple gestation, diabetes mellitus, cigarette smoking, chronic hypertension, pre-eclampsia, premature rupture of membranes, abdominal trauma, and polyhydramnios $[3,7,11]$.

Most of the studies of PA have been done in different populations of the world, with very few in Gulf countries. The aim of this retrospective study is to evaluate the interval prevalence of PA in our multinational population and feto-maternal consequences in our hospital.

Prevalence and Its Feto-Maternal Outcome in Placental Abruption

\section{Methods}

A retrospective observational study was conducted in Dubai Hospital, Dubai, UAE, from January 1, 2013 to December 31, 2017. All patients who were admitted with suspicion of PA at 28 weeks of gestation and beyond were included in the study. PA was diagnosed based on clinical signs and symptoms of vaginal bleeding, tense and tender abdomen, hypertonic uterus and was confirmed at delivery by local examination of the placenta for separation or presence of a retroplacental clot. Women with a gestational age of less than 28 weeks, women diagnosed with placenta previa, with pathology in the lower genital tract, with bleeding disorders and those with missing records of PA were excluded from the study. All data were retrieved from the maternity register, patient files and computerized hospital database. The following clinical information was collected: maternal age, gravidity, parity, antenatal care, gestational age at delivery, birth weight, and medical complications such as diabetes mellitus, hypertension, pre-eclampsia, previous cesarean section, intrauterine growth restriction and preterm premature rupture of membranes.

Maternal outcome was assessed by mode of delivery, postpartum hemorrhage, need for blood transfusion, disseminated intravascular coagulation (DIC), intensive care unit admission or multiorgan failure. Neonatal outcome was assessed by preterm birth, low Apgar score, neonatal intensive care unit admission and perinatal death. This study was approved by the Dubai scientific research ethics committee (DSREC-02/2018_04) and confidentiality of data was maintained.

The Statistical Package for the Social Sciences Version 24.0 (IBM Corp., Armonk, NY, USA) was used to analyze the data. Continuous variables were reported as means and standard deviation (SD) for bell-shaped data. For skewed data, median and range were reported. Categorical variables were reported as frequency and percentages. 
Fig. 2. Clinical presentation of placental

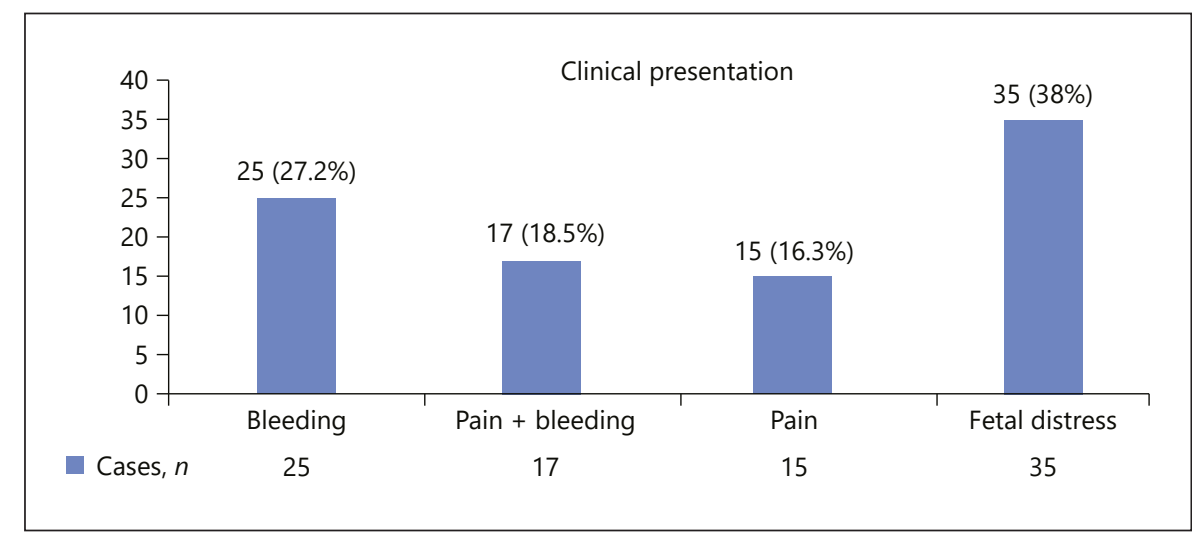
abruption.

Table 1. Demographic and obstetric risk factors associated with placental abruption

\begin{tabular}{|c|c|c|}
\hline & Cases & Percentage \\
\hline \multicolumn{3}{|l|}{ Maternal age } \\
\hline $20-34$ years & 61 & 66 \\
\hline$\geq 35$ years & 31 & 34 \\
\hline \multicolumn{3}{|l|}{ Antenatal care } \\
\hline Booked & 80 & 87 \\
\hline Unbooked & 12 & 13 \\
\hline \multicolumn{3}{|l|}{ Gravidity } \\
\hline 1 & 17 & 18 \\
\hline $2-4$ & 46 & 50 \\
\hline$\geq 5$ & 29 & 32 \\
\hline \multicolumn{3}{|l|}{ Parity } \\
\hline 0 & 21 & 23 \\
\hline $1-4$ & 60 & 65 \\
\hline$\geq 5$ & 11 & 12 \\
\hline \multicolumn{3}{|l|}{ Antenatal risk factor } \\
\hline Diabetes & 24 & 26 \\
\hline Pre-eclampsia & 18 & 19.5 \\
\hline Chronic hypertension & 2 & 2.2 \\
\hline Multiple pregnancy & 9 & 9.8 \\
\hline Previous cesarean section & 24 & 26.1 \\
\hline $\begin{array}{l}\text { Preterm premature rupture of } \\
\text { membrane }\end{array}$ & 7 & 7.6 \\
\hline Intrauterine fetal death & 7 & 7.6 \\
\hline
\end{tabular}

\section{Results}

The total number of deliveries during the study period from January 1, 2013 to December 31, 2017 was 15,079. PA was observed in 92 cases accounting for an interval prevalence of $0.61 \%(92 / 15,079)$. Out of the 92 cases, 49 (53\%) women where from the United Arab Emirates and 43 (47\%) where other nationals (Fig. 1).
Thirty-five (38\%) women had concealed abruption and $57(62 \%)$ had revealed abruption. Bleeding was the most common clinical presentation followed by a combination of pain and bleeding. There were 35 cases of fetal distress, in whom diagnosis of PA was made after delivery by placental inspection (Fig. 2).

The mean maternal age of the women was $32.0 \pm 4.8$ years, the youngest being 22 years and the eldest being 43 years old. Eighty patients who had abruption were booked cases, who had more than 3 visits in the antenatal clinic of Dubai Hospital, as compared to 12 who were unbooked. Associated antenatal risk factors observed were diabetes in 24 (26\%) patients, chronic hypertension in $2(2.2 \%)$, pre-eclampsia in 18 (19.5\%), multiple pregnancy in $9(9.8 \%)$, and preterm premature rupture of membrane in 7 (7.6\%). Out of 92 cases, only $4(4.3 \%)$ patients had a history of previous abruption, $24(26 \%)$ had a history of previous cesarean section, and 7 (7.6\%) had intrauterine growth restriction (Table 1). Regarding the mode of delivery, most of the patients with abruption were delivered by cesarean section; $78 \%$ as compared to $22 \%$ who were delivered vaginally. The postpartum outcome of our patients are summarized in Table 2 . The duration of hospitalization as inpatient exceeded 4 days for $62(67 \%)$ patients with a median of 5 days (range -2 to 37 ), showing that PA is associated with a prolonged hospital stay. There was no maternal death during the study period.

As far as neonatal outcome is concerned, it is summarized in Table 3. Thirty-five cases (40\%) were labelled as fetal distress. Median gestational age of delivery was 36 weeks (range 28-41). Forty-three cases (47\%) had a birth weight of less than $2.5 \mathrm{~kg}$. Forty-nine babies were admitted to the neonatal intensive care unit due to prematurity and a hypoxic event. Eight out of 103 babies died of intra- 
Table 2. Postpartum outcome associated with abruption

\begin{tabular}{lll}
\hline & Cases & Percentage \\
\hline Postpartum hemorrhage & & \\
$\quad$ Yes & 30 & 33 \\
$\quad$ No & 62 & 67 \\
Need for blood products & 18 & 20 \\
$\quad$ Yes & 74 & 80 \\
$\quad$ No & & \\
Duration of hospital stay & 62 & 67 \\
$\quad>4$ days & 30 & 33 \\
$\quad \leq 4$ days & 5 & 6 \\
Admission to ICU & 87 & 94 \\
$\quad$ Yes & & \\
$\quad$ No & & \\
\hline
\end{tabular}

Table 3. Fetal outcome associated with abruption

\begin{tabular}{lcc}
\hline & Babies & Percentage \\
\hline $\begin{array}{l}\text { Apgar score at } 5 \text { min } \\
\geq 7\end{array}$ & 100 & 98 \\
$\quad<7$ & 3 & 2 \\
Intrauterine fetal death & 8 & 7.7 \\
Gestational age at delivery & & \\
$\quad 28$ to $31^{+6}$ weeks & 22 & 24 \\
32 to $36^{+6}$ weeks & 26 & 28 \\
$\geq 37$ weeks & 44 & 48 \\
Birth weight & & \\
$\quad \leq 2 \mathrm{~kg}$ & 40 & 39 \\
$2.1-3 \mathrm{~kg}$ & 38 & 37 \\
$>3 \mathrm{~kg}$ & 25 & 24 \\
\hline
\end{tabular}

uterine fetal death and 1 of the 28 weeks' preterm baby died a neonatal death on day -5 of life accounting for a perinatal mortality rate of $8.7 \%$.

\section{Discussion}

In our study, we found a prevalence of abruption of $0.61 \%$, which falls within the range of $0.5-1 \%$ as reported in American, European and East Asian populations [2, 3, $6,12]$. In developing countries, the incidence is as high as $4-5 \%$. This could be due to different study populations, designs and diagnostic criteria [4]. Abruption is more common in elderly women aged more than 35 years, but this is usually observed due to multiparity, which is independent of the age factor [1]. In our study, 64\% (19/31) of our elderly patients were para 3 and above. Also, the occurrence of abruption was higher in women with multi- parity and multigravidity as compared to primigravida. Bleeding was the most common presentation in 37 (38\%) women compared to $25 \%$ reported by Tikkanen [1]. Pain or uterine hypertonia without bleeding is seen in $16 \%$ of women.

The most common antenatal risk factor in our study was diabetes mellitus (26\%), which we did not find in any previous study and this could be attributed to a high prevalence of diabetes in our population. We had $2 \%$ with chronic hypertension and $19.5 \%$ with pre-eclampsia associated with PA. In the study by Ananth et al. [14], the rate of abruption among women with or without chronic hypertension was 1.56 and $0.6 \%$, respectively. After adjustment of potential confounders, women with chronic hypertension had a 2.4-fold increased risk of abruption. Severe pre-eclampsia is a strong risk factor for PA, but some studies showed that transient hypertension and mild pre-eclampsia have also been linked to PA $[3,5,13$, 14]. Chronic diseases like hypertension and diabetes mellitus lead to placental insufficiency, which results in PA. Preterm premature rupture of the membranes before 37 weeks of gestation leads to $4-12 \%$ of cases of PA. The risk increases with decreasing gestational age at membrane rupture [15]; we had $7.6 \%$ cases of preterm premature rupture of membrane developing PA. Previous cesarean section increases the risk of PA by $30-40 \%$ in the next pregnancy in comparison to women who had vaginal delivery [16]. We had $26 \%$ of abruption cases who had a history of previous cesarean sections. The risk of PA is increased by 2 - to 3 -fold in twin pregnancy and with increasing multiplicity, the risk of $\mathrm{PA}$ also increases $[3,17]$.

PA is associated with a high risk of maternal morbidity and mortality. Bleeding caused by PA can lead to hypovolemic shock and multiorgan failure. In cases of concealed hemorrhage when placental detachment is large enough, this leads to fetal death and coagulation cascade resulting in DIC. In our study, we had 4 cases of DIC and 2 cases of acute renal injury, which were associated with intrauterine fetal death at presentation. The incidence of cesarean section was $78 \%$ in PA cases, which is much higher compared to our average cesarean section incidence of $25 \%$ in our hospital. This is mainly due to fetal distress or a previous multiple uterine scar. Maternal mortality associated with abruption has decreased from $8 \%$ in 1919 to less than $1 \%$ in 1995 and the UK confidential inquiry reported 2 maternal deaths between 2003 and 2005 [1, 18]. We had no case of mortality due to PA during our study period of 5 years in our hospital.

PA leading to fetal and neonatal morbidity and mortality is mainly associated with preterm birth, low birth 
weight and fetal distress. According to Ananth et al. [19], around $40-60 \%$ of babies are born before 37 weeks due to abruption and approximately $14 \%$ of abruption occur before 32 weeks. We had $51 \%$ of our abruption cases delivered before 37 weeks and $21 \%$ before 32 weeks. $47 \%$ cases had a birth weight of less than $2.5 \mathrm{~kg}$ and $40 \%$ had fetal distress during the intrapartum period. Forty-nine babies were admitted to the neonatal intensive care unit and 1 baby died a neonatal death within 5 days. Abruption involving more than $50 \%$ of the placental surface can lead to fetal death. We had 8 cases of intrauterine fetal death and 4 of them were associated with DIC. Perinatal mortality can be as high as $60 \%$, but in developed countries, it is in the range of $9-12 \%$ [20]. We had $8.7 \%(9 / 103)$ of perinatal mortality in our unit during this period, proving that our standards are comparable to developed countries.

\section{Conclusion}

PA is a complex disease. Although several risk factors are known, the etiopathogenesis is not fully understood and its occurrence often remained unpredictable or unpreventable. Adequate antenatal care, early identification and proper monitoring of risk factors with timely intervention may reduce the risk of PA and its feto-maternal outcome. Though the majority of our patients were booked (87\%), we still had 4 cases of stillbirth among our booked patients with adequate antenatal care. We did not have any maternal mortality and our perinatal mortality rate is comparable to that of developed countries. This shows that an appropriate multidisciplinary management strategy will enable to limit the maternal mortality, but perinatal mortality, which occurs essentially in utero, is still not preventable.

\section{Limitation of the Study}

This is a retrospective observational study, so recall bias is possible as data were gathered from the medical files. As the data came from a single hospital, the conclusions inferred may not be applicable to the entire population of the UAE. There is no comparison with a control group, so statistical significance cannot be drawn for the risk factors.

\section{Acknowledgement}

We are thankful to Dr. M.A.Z. for helping us with the statistic evaluation.

\section{Statement of Ethics}

The authors had the approval from the Dubai Scientific Research Ethics Committee (DSREC-02/2018_04).

\section{Disclosure Statement}

The authors have no conflicts of interest to disclose.

\section{Funding Sources}

Not applicable.

\section{Author Contributions}

S.S.: Idea for the proposal, literature review, ethical approval, writing up the article, communicating with statistician and submission.

L.K.H.: Literature review and reviewing the article.

A.A.: Data collection.

F.S.: Data collection.

M.A.: Data evaluation and tabulation.

\section{References}

1 Tikkanen M. Placental abruption: epidemiology, risk factors and consequences. Acta Obstet Gynecol Scand. 2011 Feb;90(2):140-9.

2 Ananth CV, Keyes KM, Hamilton A, Gissler $\mathrm{M}, \mathrm{Wu} \mathrm{C}$, Liu S, et al. An international contrast of rates of placental abruption: an ageperiod-cohort analysis. PLoS One. 2015 May; 10(5):e0125246.

3 Macheku GS, Philemon RN, Oneko O, Mlay PS, Masenga G, Obure J, et al. Frequency, risk factors and feto-maternal outcomes of abruptio placentae in Northern Tanzania: a registry-based retrospective cohort study. BMC Pregnancy Childbirth. 2015 Oct;15(1): 242.

4 Mukherjee S, Bawa AK, Sharma S, Nandanwar YS, Gadam M. Retrospective study of risk factors and maternal and fetal outcome in patients with abruptio placentae. J Nat Sci Biol Med. 2014 Jul;5(2):425-8.

5 Bibi S, Ghaffar S, Pir MA, Yousfani S. Risk factors and clinical outcome of placental abruption: a retrospective analysis. J Pak Med Assoc. 2009 Oct;59(10):672-4.
6 Hall DR Abruptio placentae and disseminated intravascular coagulopathy. Semin Perinatal.2009;33(3):189-95.

7 Jabeen M, Gul F. Abruptio placentae: risk factors and perinatal outcome. J Postgrad $3 \mathrm{Med}$ Inst. 2011;18(4):669-76.

8 Sarwar I, Abbas A, Islam A. Abruptio placentae and its complication at Ayub Teaching Hospital abbotabad. JAMCA. 2006;18(1):27-33.

9 Morgan K, Arulkumaran S. Antepartum haemorrhage. Curr Obstet Gynaecol. 2003; 13(2):81-7. 
10 Salihu HM, Bekan B, Aliyu MH, Rouse DJ, Kirby RS, Alexander GR. Perinatal mortality associated with abruptio placenta in singletons and multiples. Am J Obstet Gynecol. 2005 Jul;193(1):198-203.

11 Ananth CV, Cnattingius S. Influence of maternal smoking on placental abruption in successive pregnancies: a population-based prospective cohort study in Sweden. Am J Epidemiol. 2007 Aug;166(3):289-95.

12 Pariente G, Wiznitzer A, Sergienko R, Mazor M, Holcberg G, Sheiner E. Placental abruption: critical analysis of risk factors and perinatal outcomes. J Matern Fetal Neonatal Med. 2011 May;24(5):698-702.
13 Hung TH, Hsieh CC, Hsu JJ, Lo LM, Chiu TH, Hsieh TT. Risk factors for placental abruption in an Asian Population. Reprod Sci. 2007;14: 49-65.

14 Ananth CV, Peltier MR, Kinzler WL, Smulian JC, Vintzileos AM. Chronic hypertension and risk of placental abruption: is the association modified by ischemic placental disease? Am J Obstet Gynecol. 2007 Sep;197(3):273.e1-7.

15 Mercer BM. Preterm premature rupture of the membranes. Obstet Gynecol. 2003 Jan; 101(1):178-93.

16 Getahun D, Oyelese Y, Salihu HM, Ananth $\mathrm{CV}$. Previous cesarean delivery and risks of placenta previa and placental abruption. Obstet Gynecol. 2006 Apr;107(4):771-8.
17 Ananth CV, Smulian JC, Demissie K, Vintzileos AM, Knuppel RA. Placental abruption among singleton and twin births in the United States: risk factor profiles. Am J Epidemiol. 2001 Apr;153(8):771-8.

18 Confidential Enquiry into Maternal and Child Health. Saving mothers' lives: reviewing maternal deaths to make motherhood safer 2003-2005. London: Royal College of Obstetric and Gynaecologist; 2007.

19 Ananth CV, Berkowitz GS, Savitz DA, Lapinski RH. Placental abruption and adverse perinatal outcomes. JAMA. 1999 Nov;282(17):1646-51.

20 Ananth CV, Wilcox AJ. Placental abruption and perinatal mortality in the United States. Am J Epidemiol. 2001 Feb;153(4):332-7. 